\title{
Gramática e verdade necessária
}

\author{
João Vergílio Gallerani Cuter \\ USP \\ jv-cuter@uol.com.br
}

resumo Wittgenstein procura mostrar que a teoria dos tipos de Russell está condenada a uma autodissolução. Ela só pode ser exposta na medida em que a exposição incorre em violações sistemáticas das regras que a teoria tenta impor a toda a linguagem. Por outro lado, se for encarada enquanto mero sistema de regras para o uso de sinais, ela se torna completamente arbitrária. A teoria dos tipos apresenta na forma de uma invenção aquilo que, do ponto de vista do Tractatus, só poderia ser o resultado de uma descoberta: a estrutura essencial da realidade que a linguagem deve decalcar. É daí que surge, no Tractatus, a solução intermediária de uma "essência inefável". 0 problema se complica quando o Tractatus se revela uma alternativa inviável, e a idéia de uma estrutura essencial da realidade fica comprometida. Tento fazer, no final do artigo, uma reflexão de tipo wittgensteiniano na tentativa de determinar o que resta da noção de necessidade quando abandonamos a idéia de que a realidade possua uma estrutura essencial que a linguagem limita-se a decalcar.

palavras-chave Russell; Wittgenstein; Tractatus Logico-Philosophicus; Filosofia da linguagem; gramática; lógica; essência; representação

A distinção entre mostrar e dizer, no Tractatus, é tributária da crítica que Wittgenstein dirige à teoria dos tipos de Russell. Gostaria de começar nosso diálogo recuperando o exato teor dessas críticas. Se não me engano, uma compreensão adequada deste ponto é capaz de nos levar a uma discussão interessante a respeito da própria noção de necessidade lógica, ganhando assim um interesse que vai muito além da mera exegese textual.

Recebido em 12 de março de 2009. Aceito em 23 de agosto de 2009.

doispontos, Curitiba, São Carlos, vol. 6, n. 2, p.129-144, outubro, 2009 
Uma teoria dos tipos filosoficamente conseqüente pressupõe sempre uma concepção com posicional do significado associada a uma concepção referencial das partes sentenciais.

Chamo de concepção composicional do significado qualquer tentativa de tomar o sentido sentencial como uma função do significado das partes isoladas da sentença. Isto quer dizer apenas que, para o defensor desta concepção, bastaria determinar o conteúdo semântico das partes sentenciais para que o conteúdo semântico da sentença como um todo estivesse imediatamente determinado. É claro que, descrita desta maneira, esse tipo de concepção abre-se imediatamente a uma série de objeções mais ou menos familiares. Deveríamos ser capazes, por exemplo, de distinguir os sentidos de proposições que, apesar de compostas exatamente das mesmas partes, têm sentidos muito diferentes. Uma coisa, como todos sabem, é amar uma pessoa. Outra, muito diferente, é ser amado por ela. A ordem em que os elementos sentenciais são introduzidos parece fazer uma enorme diferença nestes casos, e parece contribuir, por isso, para a determinação do sentido da sentença como um todo. Além disso, é preciso tomar uma decisão a respeito da contribuição semântica das chamadas "constantes lógicas". Se levamos o princípio composicional a ferro e fogo, então até mesmo as constantes lógicas que fazem parte de uma sentença devem ter um "significado" capaz de se "compor" com as outras partes sentenciais para produzir um sentido. Fica difícil, então, dar conta da aparente identidade de sentido existente, por exemplo, entre uma proposição $p$ qualquer e a negação de sua negação. Finalmente, é preciso dar conta da própria noção de "parte sentencial". Toda a teoria das descrições de Russell, por exemplo, está baseada na distinção entre componentes genuínos da proposição e componentes apenas aparentes.

A teoria dos tipos, por sua vez, é uma tentativa de dar conta de uma quarta dificuldade. Nem toda composição de elementos significativos parece dar origem a uma sentença com sentido. Parece fazer sentido dizer que Sócrates é mortal, mas não faz sentido nenhum dizer que a mortalidade é mortal. Ou seja, parece ser perfeitamente possível concatenar elementos sentenciais individualmente significativos e, mesmo assim, obter como resultado um contra-senso. Este tipo de consideração parece depender excessivamente de uma certa intuição lingüística a respeito do 
que é um contra-senso e do que é uma simples falsidade. No entanto, a aceitação de uma composicionalidade irrestrita, tal como Russell havia aceitado nos Principles of Mathematics, nos conduz a paradoxos no âmbito da lógica. Se faz sentido atribuir uma propriedade a ela mesma, então parece que deve fazer sentido também falarmos na propriedade que determinadas propriedades possuem de não serem possuídas por si mesmas. O paradoxo de Russell parece surgir exatamente dessa admissão. Foi exatamente isto que forçou Russell a abandonar o princípio irrestrito de composicionalidade, e a propor as restrições composicionais características da teoria dos tipos.

Num primeiro momento, a teoria dos tipos surge investida de um forte apelo intuitivo. Surge, na verdade, como uma espécie de retorno à intuição de que partimos - a de que não faz sentido dizer que a mortalidade é (ou deixa de ser) mortal. Isto não parece ser verdadeiro nem falso. Parece ser apenas um amontoado desconexo de palavras, e é exatamente assim que a teoria dos tipos irá tratar pseudoproposições dessa espécie. No entanto, como a teoria surge num contexto teórico em que a doutrina referencialista do significado estava em vigor, ela tem uma conseqüência ontológica imediata que foi muito bem percebida por Wittgenstein. À exclusão lógica de determinadas concatenações de palavras deve corresponder, nesse ambente referencialista, uma exclusão ontológica de determinadas combinações das coisas a que as palavras se referem. A teoria dos tipos de Russell estava desde o início condenada a ser uma descrição direta ou indireta da estrutura essencial da realidade. É isso que, segundo Wittgenstein, condenava-a a se autodissolver no próprio âmbito dos contra-sensos que ela pretendia afastar.Vejamos como isso acontece.

Por que a sentença "A mortalidade é mortal" deve ser considerada um contra-senso? Segundo a teoria dos tipos, isso ocorre porque a palavra "mortalidade" é simplesmente um artificio lingüístico que estamos usando, neste caso, para substantivar o próprio predicado "... é mortal", acomodando-o às regras do português para que possa ocupar o lugar de sujeito gramatical da sentença. Como não é permitido construir uma sentença no português que tenha a forma "é mortal é mortal", nós substituímos a primeira ocorrência da expressão "é mortal" pela expressão substantiva "a mortalidade", pressupondo que as duas expressões designam, no entanto, exatamente o mesmo objeto. $O$ procedimento nada tem 
de tão estranho, tomado em si mesmo. Afinal de contas, se digo que Sócrates é mortal, o que estou afirmando é que a mortalidade "convém" a Sócrates. Em outras palavras, estou afirmando que a entidade designada pelo predicado "é mortal" (ou seja, a mortalidade) está unida à entidade designada pelo sujeito "Sócrates", formando um complexo que torna a sentença "Sócrates é mortal" verdadeira. O erro, do ponto de vista da teoria dos tipos, não está nesse procedimento, mas sim na violação de uma certa ordem categorial. A mortalidade é uma propriedade de indivíduos, e não um indivíduo, como Sócrates. Em função disto, a expressão que nomeia a mortalidade não pode ocupar o lugar de expressões que nomeiam indivíduos, como é o caso do nome próprio "Sócrates". Não importa que essa expressão seja o substantivo "mortalidade", ou a expressão predicativa "é mortal". Muito embora "A mortalidade é mortal" seja uma expressão passável do ponto de vista da gramática normativa do português, ela deve ser denunciada, no nível da gramática lógica, como um contra-senso.

Aqui, no entanto, cria-se uma situação curiosa. Examinemos com mais cuidado uma das sentenças que enunciamos no arrazoado que acabamos de fazer. Eu afirmei, dando voz à teoria dos tipos, que a mortalidade é uma propriedade de indivíduos, e não um indivíduo, como Sócrates. Existem aqui três sentenças envolvidas: "Sócrates é um indivíduo", "A mortalidade não é um indivíduo" e "A mortalidade é uma propriedade de indivíduos". Analisemos as duas primeiras. A segunda nega da mortalidade exatamente aquilo que a primeira afirma a respeito de Sócrates. A utilização dessas duas sentenças pressupõe que a individualidade possa ser afirmada significativamente tanto de indivíduos, como Sócrates, quanto de propriedades de indivíduos, como a mortalidade. A afirmação será verdadeira, no caso de Sócrates, e falsa, no caso da mortalidade, mas a teoria dos tipos de Russell exige que as duas afirmações façam sentido. Isso, por si só, já nos põe diante de um sério problema de alocação categorial do predicado "ser um indivíduo". Apesar de poder ser atribuído a Sócrates, ele não poderia designar uma propriedade de indivíduos, como a mortalidade, já que deve ser atribuído significativamente a propriedades de indivíduos. Na verdade, ele deve poder ser atribuído significativamente a qualquer entidade de qualquer nível da hierarquia dos tipos, já que a teoria incorpora a negação da individualidade a qualquer entidade que 
não pertença ao nível dos indivíduos. Em particular, isto é verdadeiro da própria individualidade, que certamente não é um indivíduo. Nesse ponto, estaremos de volta ao âmbito das propriedades que não possuem a si mesmas, e o paradoxo de Russell terá livre curso novamente.

Creio que nosso primeiro impulso, neste ponto, é tentar um desvio desse tipo de conseqüência por meio de um recurso a regras semânticas. Ao invés de nos referirmos diretamente a indivíduos e propriedades de indivíduos, a Sócrates e à mortalidade, poderíamos tentar nos referir apenas a nomes de indivíduos e a predicados individuais, ao nome "Sócrates" e ao predicado "é mortal". Justificaríamos a exclusão do contra-senso "A mortalidade é mortal" referindo-nos às partes sentenciais elas mesmas, e não àquilo que essas partes designam. Ao invés de alegar que a mortalidade é uma propriedade de indivíduos, e não um indivíduo, como Sócrates, alegaríamos que a expressão "é mortal" é um predicado individual que só pode se unir a nomes de indivíduos para formar sentenças significativas. Mas o que queremos dizer exatamente com esta última alegação? Em especial, o que queremos dizer quando afirmamos que a expressão "é mortal" não pode unir-se à expressão "mortalidade"? Certamente não queremos dizer que seja logicamente impossível justapor os dois sinais sobre uma folha de papel. Isso não apenas é possível, como é também um fato - essas expressões estão justapostas sobre esta folha de papel, por exemplo, um pouco mais acima. O verbo "poder", nesse caso, tem claramente um sentido deôntico. Quando dizemos que essas expressões não podem ser justapostas, queremos dizer que isto é proibido por uma regra da gramática lógica que nós decidimos adotar. Dissemos "não podem", mas seria mais exato dizer "não devem".

Muito bem, então. Fiquemos apenas com as regras, e deixemos de lado as afirmações ontológicas a respeito das possibilidades e impossibilidades combinatórias que dizem respeito às próprias entidades referidas pelas partes sentenciais. O que poderíamos dizer a respeito destas regras lingüísticas? Elas são arbitrárias? Poderiam ser diferentes do que são? $\mathrm{Ou}$ será que elas refletem, no nível deontológico, necessidades ontológicas de fundo? Suponhamos que elas sejam meramente arbitrárias. Elas seriam um meio, entre muitos outros possíveis, de se evitar o surgimento de contradições semelhantes ao paradoxo de Russell. Não haveria, neste caso, nenhuma garantia de espelhamento, na linguagem, das articulações 
lógicas constitutivas do mundo que a linguagem pretende descrever. Esta postura, unida à teoria referencial do significado, tem conseqüências dificilmente aceitáveis. Se proibições feitas no nível da gramática lógica não têm nenhuma conexão forte com impossibilidades estritamente ontológicas, então é bem possível que nossas convenções tenham deixado uma grande quantidade de fatos fora do alcance de qualquer descrição possível.Tudo se passa como se ficasse em aberto a possibilidade ontológica de a mortalidade ser de fato mortal, fechando-se apenas a possibilidade de articularmos lingüisticamente a afirmação da ocorrência desse fato. Ou, de maneira equivalente, poderia até ser um fato que a mortalidade não é mortal, mas nós estaríamos impedidos de dizer isso, sob pena de ficarmos reféns de paradoxos quando fôssemos construir nossas teorias. Tudo que poderíamos descrever seriam as regras que adotamos no âmbito lingüístico por razões de ordem técnica.

As conseqüências são muito mais drásticas se examinamos a questão pelo outro lado - o lado das conexões lingüísticas permitidas por regras que tomássemos como puramente arbitrárias. A doutrina referencial do significado está vinculada a um horizonte de correspondência entre linguagem e mundo. Uma sentença elementar é verdadeira caso os objetos introduzidos pelas partes sentenciais estejam de concatenados no mundo, e é falsa caso eles não estejam. Uma postura convencionalista quanto às regras da gramática lógica nos leva, deste ponto de vista, ao pior dos mundos. Se nossas convenções arbitrárias podem ter excluído a expressão de conexões possíveis apenas com a finalidade de evitar o inconveniente dos paradoxos, então elas também podem ter incluído a expressão de conexões ontologicamente impossíveis. Nossas regras arbitrárias permitem a formação da sentença "Sócrates é mortal", e nossa teoria referencial do significado nos garante que o nome "Sócrates" designa um indivíduo, e o predicado "é mortal" designa uma propriedade de indivíduos. No entanto, nada nos garante que essa combinação seja de fato possível. Talvez isso seja apenas uma conexão lingüística à qual não corresponde nenhuma possibilidade ontológica real. A referência transforma-se, assim, num salto no vazio. A palavra "Sócrates" nos remete a um componente do mundo, e a palavra "mortalidade" nos remete a outro. Mas só Deus sabe se a sentença "Sócrates é mortal" nos remete a uma possibilidade do mundo, ou não. Todo o horizonte de correspondência 
aberto pela teoria referencial fica comprometido, e a referência dos nomes perde qualquer relevância para a questão da verdade. A referência transforma-se numa relação solta e logicamente inoperante.

A única alternativa seria dizer que a teoria dos tipos, enquanto teoria, diz respeito apenas ao simbolismo, mas que as estipulações que ela faz no nível simbólico nada têm de arbitrário. Diríamos que elas espelham uma ordem necessária inscrita na estrutura última do mundo, que não pode, no entanto, ser descrita pela linguagem, sob pena de incorrermos em contradições. As estipulações da teoria dos tipos diriam respeito unicamente ao simbolismo. Seriam, nos termos do Tractatus, uma "teoria correta do simbolismo". Ao mesmo tempo, no entanto, suas bases estritamente lógicas nos garantiriam que as estipulações simbólicas ali feitas nos mostram a estrutura da realidade, sem no entanto, poder dizê-la. É a esta posição que Russell seria inevitavelmente conduzido, caso sua filosofia fosse dotada do grau de profundidade e conseqüência que encontramos na filosofia de Wittgenstein.

$\mathrm{Na}$ verdade, porém, mesmo que se comprometesse com a distinção entre mostrar e dizer, a teoria dos tipos de Russell ainda seria filosoficamente insatisfatória. Há, é claro, o problema associado aos axiomas da infinitude e da irredutibilidade, mas não são esses problemas que me interessam aqui. Há um outro problema, bem mais profundo e de conseqüências muito mais sérias, que devemos examinar. A teoria dos tipos é, na verdade, uma extensão da distinção feita por Frege entre conceitos e objetos. Dada uma sentença como "Sócrates é mortal", Frege distinguia aqui dois componentes: o nome "Sócrates", que seria uma unidade lingüística completa, o a função proposicional "...é mortal", que conteria um lugar vazio e seria, neste sentido, carente de complementação, "insaturada". Aceitando a teoria composicional do significado, Frege afirmava que a primeira expressão tinha como referência um objeto, e a segunda, um conceito. Por analogia com suas designações lingüísticas, o objeto deveria ser pensado como uma entidade "saturada", ao passo que o conceito deveria ser pensado como uma entidade carente de complementação. Não é muito claro o que deveríamos entender exatamente por esta oposição no nível ontológico. Parece haver aqui apenas a pretensão minimalista de se postular uma ordem combinatória no nível das referências que espelhe a ordem combinatória constitutiva da conceitografia. 
Funções proposicionais como "...é mortal" podem complementar funções proposicionais de ordem superior, como a expressão "existe algo que...", mas não podem complementar funções proposicionais do mesmo tipo que elas. A estas possibilidades e impossibilidades combinatórias no nível simbólico corresponderiam possibilidades e impossibilidades combinatórias no nível ontológico. O que a teoria dos tipos faz é simplesmente estender esta idéia básica a toda a hierarquia de funções proposicionais postulada para contornar os paradoxos da auto-referência. A hierarquia dos tipos, sendo uma hierarquia de entidades, e não meramente de expressões lingüísticas, redunda portanto na postulação logicamente induzida da ordem combinatória a partir da qual se constitui toda a trama da realidade. Qualquer mundo possível é composto de concatenações de entidades segundo a ordem combinatória dada pela teoria dos tipos. Na base da hierarquia, Russell coloca as velhas e boas "entidades saturadas" de Frege, rebatizadas - os indivíduos. Nos andares de cima, entidades insaturadas de diversos tipos, com sua identidade lógica definida pelas possibilidades e impossibilidades combinatórias que elas trariam inscritas em sua própria natureza.

Nada disso sobrevive no Tractatus, a começar da distinção fregiana entre conceito e objeto. Todo objeto passa a ser tratado como se fosse um conceito fregiano - uma entidade insaturada, carente de complementação, que o mundo é incapaz, digamos assim, de exemplificar isoladamente. Uma proposição é uma síntese de funções proposicionais, e um estado de coisas é uma ligação imediata de conceitos. A terminologia não deve nos desencaminhar neste ponto. Objetos tractarianos têm sempre uma forma lógica determinada - incorporam em sua própria natureza uma certa ordem de possibilidades e impossibilidades combinatórias. A idéia de Wittgenstein é a seguinte. Mesmo que, no final das contas, a estrutura do mundo coincidisse com aquela proposta por Frege ou por Russell, não faria sentido fazer uma cisão entre objetos, de um lado, e conceitos, de outro. A função proposicional "...é mortal" tem um lugar vazio, que pode ser preenchido por nomes como "Sócrates", mas isso só quer dizer que "Sócrates" também tem um lugar vazio, que só pode ser preenchido por funções proposicionais como "...é mortal". Os objetos tractarianos, por isso, têm a identidade lógica que Frege atribuía aos conceitos, e não àquilo que ele chamava de "objetos" e Russell de "indi- 
víduos". Todo nome, no Tractatus, é uma função proposicional, e todo objeto é, nesse sentido, um "conceito" - carente de complementação.

Mas a principal ruptura não ocorre neste ponto. O que leva Wittgenstein a condenar toda a teoria dos tipos é o fato de ela propor, na forma de uma invenção, aquilo que só poderia ser obtido na forma de uma descoberta - a estrutura lógica do mundo. Motivado pela necessidade de evitar os paradoxos da auto-referência, Russell construiu uma hierarquia de expressões, baseando toda a gramática lógica numa série de regras que tomavam como base o lugar relativo que cada expressão ocupava dentro dessa hierarquia. Como ele pretendia conservar a teoria composicional e a teoria referencial do significado, teve que aceitar a conseqüência inevitável: a postulação a priori de uma ontologia baseada numa construção lógica. Russell literalmente inventou uma ontologia, e é esse o absurdo que o Tractatus tenta denunciar. É possível determinar a priori que proposições são essencialmente complexas. É possível também determinar a priori que essa complexidade se resolve em elementos inanalisáveis. Finalmente, é possível determinar a priori que esses elementos inanalisáveis designam objetos logicamente simples que se estruturam segundo uma certa ordem de possibilidades e impossibilidades combinatórias. Tudo isso exige apenas o pressuposto geral de que nós representamos o mundo - fazemos "figurações de fatos", como diz o Tractatus. O dado da representação desempenha aqui um papel muito semelhante ao que é atribuído ao dado do conhecimento no sistema kantiano. Partimos dele, para ir em busca de suas condições de possibilidade. Mas o dado da representação não me obriga a postular a existência da hierarquia dos tipos de Russell. A determinação dos nomes logicamente simples e dos objetos designados por esses nomes só pode ser um apêndice da lógica, nunca o seu prefácio. Eles devem ser descobertos, e não inventados. Devem ser revelados, e não antevistos. Sabemos de antemão que os objetos têm uma certa ordem categorial, que permite certas combinações, e exclui outras. Mas não sabemos que combinação é essa, nem podemos saber, antes de termos chegado ao final do processo de análise.

De todo modo, mesmo após o processo de análise, jamais poderemos descrever essa ordem categorial. Isso quer dizer apenas que as possibilidades e impossibilidades combinatórias de um objeto não se deixam apreender na forma de uma concatenação de objetos. Se Sócrates for 


\section{8}

mesmo um objeto simples, e pertencer a uma categoria que resolvermos chamar de "indivíduos", a individualidade de Sócrates não será algo "destacável" dele, que Sócrates poderia, digamos assim, não possuir. Será uma propriedade interna do objeto, inseparável dele. A sentença "Sócrates é um indivíduo" não seria capaz de dizer nada que o nome "Sócrates" já não tivesse dito. E o nome "Sócrates", sozinho, não diz nada. "Sócrates é um indivíduo" não é uma proposição. É apenas a tentativa absurda de articular proposicionalmente um simples nome. Nesse sentido é um contra-senso.

O Tractatus, portanto, realiza com radicalidade máxima (e total autoconsciência) o ideal que estava latente na teoria dos tipos de Russell: o ideal de uma ontologia logicamente determinada, mas em última instância inefável. A teoria da figuração do Tractatus é, como tentei demonstrar há muitos anos, em minha tese de doutoramento, uma teoria dos tipos despida da ilusão da descoberta e de qualquer pretensão descritiva.

Tudo isso oferece farto material para reflexão. Todo o edifício tractariano estava baseado nos princípios da composicionalidade do sentido proposicional e da referencialidade das partes proposicionais. Toda a filosofia madura de Wittgenstein está baseada justamente na negação desses dois princípios e de uma série de outras teses que pareciam decorrer deles. Ainda assim, o problema da ordem categorial inscrita em nossa linguagem permanece latente, exigindo um tratamento novo, que não dependa da postulação de objetos logicamente simples exibindo sua inefável combinatoriedade. O que está envolvido, por exemplo, na impossibilidade de descrevermos um objeto como sendo vermelho e amarelo ao mesmo tempo? Não me refiro aqui a objetos que tenham uma tonalidade alaranjada, mas a objetos que fossem, no mesmo lugar e ao mesmo tempo, tão vermelhos quanto uma maçã, e tão amarelos quanto o ouro? $\mathrm{Ou}$, se preferirem tomar o exemplo das tonalidades intermediárias, o que está envolvido na impossibilidade de descrevermos um objeto como tendo uma tonalidade vermelha esverdeada? Uma resposta telegráfica possível seria dizer que temos regras socialmente acordadas para o uso do vocabulário das cores, e que essas regras nos proíbem de fazer descrições utilizando estas expressões. De um certo ponto de vista, é isso, mesmo. Mas eu gostaria de ruminar um pouco tanto o problema 
quanto essa suposta solução. Afinal de contas, alguém poderia, não sem alguma razão, alegar que, até aí, morreu o Neves. Pois permanece a questão de saber se estas regras estão ligadas a alguma necessidade última e irredutível situada fora dos limites da linguagem - necessidade que daria, por assim dizer, o pano de fundo para a instituição dessa regra. Dizendo de outra maneira, poderíamos perguntar se, apesar de arbitrárias, essas regras não deveriam, a seu próprio modo, conformar-se a uma certa estrutura da realidade ou da percepção que é logicamente anterior a elas.

Se tentarmos responder positivamente a uma questão como esta, teremos aberto diante de nós o seguinte horizonte. Deveríamos reconhecer a existência de muitos sistemas de convenções lingüísticas muito diferentes entre si que estaríamos dispostos a chamar de "linguagem". Apesar disso, nossa resposta positiva nos convidaria a imaginar que todos esses sistemas tenham que confrontar uma mesma estrutura, que limita nossas possibilidades de escolha de algum modo. Nosso sistema nos proíbe de dizer que um objeto qualquer é vermelho esverdeado. Esta regra é arbitrária no sentido de ser uma convenção, mas o ponto de vista que assumimos nos obrigaria a reconhecer que esta convenção não foi feita com total autonomia, "no vazio". Estamos supondo que esta convenção teve que se ajustar ao ambiente de possibilidades criadas pela vida humana em geral - por aquilo que poderíamos chamar de "forma humana de vida". Entre as características presentes nessa "forma de vida" humana estaria justamente sua estrutura perceptiva. Somos capazes de perceber o vermelho, mas não somos capazes de perceber nada que estaríamos dispostos a chamar de "verde avermelhado". Por isso, excluímos a expressão "verde avermelhado" de nosso estoque de expressões cromáticas. Não apenas a excluímos, como tínhamos mesmo que excluí-la. A regra não "criaria", deste ponto de vista, a impossibilidade de haver um verde avermelhado, mas "seria induzida" por ela. Em última análise, a exclusão lógica da atribuição do predicado "verde avermelhado" a algo estaria assentada na exclusão ontológica de uma cor que pudesse ser chamada de "verde avermelhado".

Examinemos com calma cada uma das afirmações que fizemos. O que pode querer dizer a afirmação de que não podemos perceber nada que estaríamos dispostos a chamar de "verde avermelhado"? Em princípio, quer dizer apenas que não fizemos nenhuma convenção para aplicar a expressão "verde avermelhado" enquanto determinação cromática de 
nosso campo perceptivo. Mas, interpretada dessa maneira, a afirmação perde todo e qualquer caráter explicativo. Nada nos autorizaria a dizer que "por isso" excluímos a expressão "verde avermelhado" de nosso estoque de expressões cromáticas. Dizer isso seria dizer simplesmente que fizemos determinadas convenções porque as fizemos. Mas até mesmo no português isso, ou bem não diz coisa nenhuma, ou bem redunda apenas numa forma enfática de dizer que nossas convenções foram feitas arbitrariamente. Como quando dizemos "Fui viajar, porque fui viajar, e pronto." O que buscávamos era uma expressão para o fundamento da regra, para uma razão última para a regra ser como é. O que obtivemos, porém, foi bem menos do que isso. $O$ resultado líquido foi a mera repetição enfática da regra.

Abdiquemos, então, da expressão cautelosa "nada que estaríamos dispostos a chamar de". Partamos para a expressão aberta e franca da dependência: "Excluimos a expressão 'verde avermelhado' porque não somos capazes de perceber coisas verdes avermelhadas". O que pode querer dizer a sentença "não somos capazes de perceber coisas verdes avermelhadas"?

Uma primeira resposta, muito simples, mas também bastante razoável, seria dizer que essa sentença, em princípio, não quer dizer coisa nenhuma. Nossas regras excluem a expressão "verde avermelhado", e o que a sentença com que tentamos justificar a regra fez foi simplesmente usar a expressão que as regras excluíam. Mais precisamente, o que nós fizemos foi utilizar a expressão para fazer uma determinação cromática, ao passo que nossas regras estavam excluindo exatamente esse tipo de determinação. Podemos imaginar alguém dizendo-se incapaz de perceber, ou imaginar, ou reconhecer o vermelho - na boca de um daltônico isto equivaleria à confissão de que ele se sente incapaz de fazer distinções cromáticas que nós todos fazemos. Nós poderíamos entender perfeitamente o que ele diz. Mas dizer que eu não sou capaz de perceber o vermelho esverdeado tem tanto sentido quanto confessar que eu sou capaz de ouvir o vermelho. Temos aqui, portanto, uma situação perfeitamente análoga àquela que levara Wittgenstein, no Tractatus, a postular a inefabilidade das inserções categoriais dos objetos. Quando tentamos dizer aquilo que está na base de uma regra da gramática lógica, somos levados a violar exatamente aquela regra lógica que estávamos querendo justificar. 
Mas será que é necessário que seja sempre assim? Gostaria de trazer à consideração de vocês alguns casos em que a sentença "não somos capazes de perceber o verde avermelhado" ganha um sentido preciso e inobjetável. Imaginemos alguém que se declarasse capaz de perceber coisas verdes avermelhadas. Algo que chamaríamos simplesmente de "verde", ele chama por vezes de "verde avermelhado". Notamos, então, que ele usa a expressão de maneira bastante sistemática para referir-se a uma certa tonalidade muito escura de verde, e a nenhuma outra cor. Seu comportamento verbal fica previsível. Podemos facilmente identificar os objetos que ele descreveria utilizando essa expressão. Não diríamos que ele percebe uma cor que não somos capazes de perceber, mas apenas que resolveu referir-se a uma cor familiar com uma terminologia estranha. No final das contas, ele faz as mesmas distinções cromáticas que fazemos, e não temos por que nos sentirmos todos daltônicos em relação a ele. Ele não é "capaz de perceber" uma cor que não percebemos. Ele apenas se refere a elas de um modo ligeiramente diverso. Ele apenas chama de "verde avermelhado" coisas que não estaríamos dispostos a chamar assim. E, novamente, aquilo que pretendia se apresentar como um fundamento de nossas regras, irá reaparecer como a mera reenunciação dessas regras.

Mas as coisas podem não ser tão simples. Suponha que esse Fulano veja uma coisa alaranjada e outra com a tonalidade de verde que ele chama de "verde avermelhado". Diante dessas duas coisas, ele nos diz que elas têm uma coloração "semelhante", pois ambas têm cores "avermelhadas". Ou seja, ali onde não vemos semelhança cromática nenhuma, ele vê alguma. Neste caso, não podemos falar apenas num deslocamento lingüístico. Essa pessoa está afirmando que vê uma semelhança num caso em que não somos capazes de ver semelhança alguma. Mais do que isso, ela afirma estar percebendo uma semelhança de um tipo que nos é perfeitamente familiar. Se nos mostrarem um azul avermelhado e um amarelo avermelhado, nós também poderíamos afirmar que essas duas tonalidades têm em comum a vermelhidão. O que dizer diante disso? Esse caso comporta diversos graus e diversas variantes que não irei analisar aqui. Um ponto, no entanto, me parece claro. Em princípio, a afirmação feita por essa pessoa faz pleno sentido e, mais do que isso, ela se insere no jogo da bipolaridade, na oposição entre o verdadeiro e o falso. É perfeitamente possível que nos perguntemos se ele está sendo sincero 


\section{2}

ou não, e podemos, inclusive, aplicar a seu proferimento os critérios usuais que utilizamos para avaliar a sinceridade de um relato perceptivo. Procuraremos saber se essa pessoa é habitualmente veraz, se tem alguma razão para estar mentindo, e assim por diante.

O curioso é que, visto retrospectivamente, o primeiro enunciado parece ganhar, agora, novos contornos. Se essa pessoa me diz estar vendo algo verde avermelhado, eu não posso mais me contentar em dizer que ela está chamando de "verde avermelhado" uma cor que eu chamaria de "verde escuro". Serei obrigado a reconhecer que, se ela diz mesmo a verdade, então ela é capaz de ver uma cor que eu não vejo, e que essa cor é um verde com tonalidade avermelhada. E ela será, também, obrigada a reconhecer que não vê a cor que todos nós vemos: o verde escuro, que não tem nenhum matiz de vermelho.

Inserida neste contexto discursivo, a afirmação "não somos capazes de ver um verde avermelhado" saltou para outra categoria. Deixou de ser o mero enunciado oblíquo de uma regra lingüística, para se tornar um enunciado empírico a respeito de nossas capacidades perceptivas. Por oposição a essa pessoa, que, ao que tudo indica, é capaz de enxergar uma cor que nenhum de nós enxerga, minha incapacidade de ver o verde avermelhado aparece como uma singularidade perceptiva que determinadas pessoas têm, e outras, não.

Até aqui, estamos examinando o caso de uma pessoa que vê o mesmo número de cores e tonalidades que nós vemos. Onde fazemos uma distinção simples, ela também faz. Nossa discordância se dá apenas no momento de afirmar proximidades e distâncias cromáticas. Ela traça as distinções no mesmo ponto em que as traçamos, mas de um outro modo. Procurei mostrar que seria perfeitamente imaginável que a expressão "verde avermelhado", que para nós não tem nenhuma espécie de aplicação, passaria a ter uma aplicação precisa neste caso. Mas podemos também estabelecer o mesmo ponto imaginando uma pessoa capaz de ver coisas que nós não vemos, nem somos capazes de ver. Uma cor inexistente, por exemplo. Diante de um quadro no qual qualquer um de nós enxergaria um branco mais ou menos uniforme, essa pessoa veria uma mancha no centro do quadro que não é nem preta, nem verde, nem amarela, etc. Do ponto de vista dessa pessoa, todos nós somos daltônicos, e nosso sistema de referência cromático é claramente incompleto. 
Curiosamente, isto nos parece trazer de volta a um universo conceiOtual mais ou menos próximo da teoria da figuração do Tractatus. Embora nossas regras lingüísticas não sejam logicamente determinadas pela ordem categorial vigente no domínio atemporal dos objetos, elas podem ser vistas como o resultado de um atrito entre decisões arbitrárias e contingências naturais completamente externas ao âmbito dos conceitos. Mesmo abandonando a ilusão de um decalque único e necessário de uma ordem ontológica dada de uma vez por todas, não haveria razão para pensarmos que estamos trancafiados no interior de uma "espontaneidade dos conceitos" perfeitamente indiferente ao mundo. Nossas regras foram feitas no mundo e para o mundo, e não teriam como se inserir no universo humano ignorando o modo como esse mundo se apresenta para nós. Em grande medida, as regras são obrigadas a acompanhar a partitura ontológica que lhes é apresentada por esse mundo em seus contornos mais gerais, mais ou menos como um músico que improvisa sobre uma seqüência harmônica dada de antemão. $\mathrm{O}$ improviso está claramente subdeterminado pela seqüência harmônica, já que muitas outras linhas melódicas seriam igualmente compatíveis com aquela seqüência fixa de acordes. Mas o improviso não pode ser cego aos acordes. O solista não pode ir simplesmente tocando as notas que bem entende.

A lógica nasce exatamente desse atrito. Sua necessidade não é de maneira alguma o espelho de uma ordem ontológica necessária, quando por mais não seja, porque a ordem que ela em alguma medida e de algum modo espelha nada tem de necessária. É assim, mas poderia ser diferente. É esta, mas poderia ser outra. A necessidade própria da lógica é de natureza deôntica, e nasce de decisões arbitrariamente tomadas e se mantém graças a um sistema de avaliação que separa, não o verdadeiro do falso, mas o correto do incorreto. Ela é muito mais semelhante, deste ponto de vista, a um ordenamento jurídico do que a um espelho. Como todo ordenamento jurídico, porém, ela está condenada a espelhar, em alguma medida, a realidade sobre a qual ela pretende se aplicar. Se os leões tivessem o seu ordenamento jurídico, ele seria completamente inaplicável ao universo humano. Nós não conseguiríamos inserir as suas regras naquilo que nos é dado anteriormente à própria regra - nossa forma humana de vida. Do mesmo modo, e no mesmo sentido, se os leões tivessem uma linguagem, nós não conseguiríamos compreendê-los. 


\section{4}

Suas regras seriam uma improvisação que segue uma seqüência harmônica diferente da nossa e, em grande parte, inacessível para nós. Como as nossas, as regras arbitrariamente eleitas pelos leões também mostrariam uma certa forma de vida. A partir de um ponto, porém, elas seriam completamente opacas. Nós podemos tentar imaginar como se sente a mãe que perde seu filho, mas não saberíamos por onde começar um exercício de imaginação que nos levasse ao sentimento que tem a leoa que perde seu filhote. Isto é tão impossível para nós quanto imaginar o verde avermelhado. Não há, porém, nenhuma barreira lógica envolvida aqui. Existem apenas fatos da natureza, que nosso ordenamento lógico teve que tomar como um pano de fundo inescapável para poder se qualificar como instância reguladora dos proferimentos lingüísticos de um certo animal. 